\title{
Some Hybrid Geometric Aggregation Operators with 2-tuple Linguistic Information and Their Applications to Multi-attribute Group Decision Making
}

\author{
Shu-Ping Wan ${ }^{\text {a,b }}$

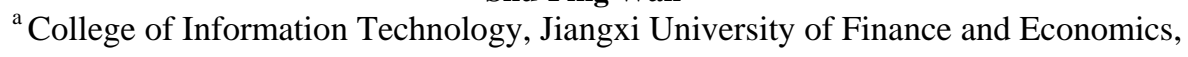 \\ Nanchang, Jiangxi 330013, China \\ bJiangxi Key Laboratory of Data and Knowledge Engineering, Jiangxi University of Finance and Economics,
} Nanchang 330013

E-mail: shupingwan@163.com

Received 30 September 2011

Accepted 1 December 2012

\begin{abstract}
A new method is developed to solve multi-attribute group decision making (MAGDM) problem in which the attribute values, attribute weights and expert weights are all in the form of 2-tuple linguistic information. First, the operation laws for 2-tuple linguistic information are defined and the related properties of the operation laws are studied. Then, some new hybrid geometric aggregation operators with 2-tuple linguistic information are developed, involving the 2-tuple hybrid weighted geometric average (THWAG) operator, the 2-tuple hybrid linguistic weighted geometric average (T-HLWG) operator and the extended 2-tuple hybrid linguistic weighted geometric average (ET-HLWG) operator. These hybrid geometric aggregation operators generalize the existing 2-tuple linguistic geometric aggregation operators and reflect the important degrees of both the given 2-tuples and the ordered positions of the 2-tuples. In the proposed decision method, using the ET-HLWG operators the individual overall preference values of the alternatives are integrated into the collective ones of the alternatives, which are used to rank the alternatives. The method can sufficiently consider the importance degrees of different experts and thus relieve the influence of those unfair arguments on the decision results. A real example of evaluating university faculty is given to illustrate the proposed method and the comparison analysis demonstrates the universality and flexibility of the proposed method in this paper.
\end{abstract}

Keywords: Multi-attribute group decision making; Linguistic preference; 2-tuple linguistic information; hybrid aggregation operator 


\section{Introduction}

Multi-attribute group decision making (MAGDM) problems with linguistic information arise from a wide range of real-world situations (Jiang et al. ${ }^{1}$; Herrera and Herrera-Viedma ${ }^{2}$; Parreiras et al. $^{3}$ ). In linguistic MAGDM analysis, firstly, experts provide their assessment information from the pre-established linguistic term sets. Then the linguistic information provided by experts is aggregated to form a collective opinion on the alternatives and the most desirable alternative(s) can be selected according to the derived collective opinion (Herrera et al. ${ }^{4}$; Jiang et al. ${ }^{1}$; $\mathrm{Xu}^{5,6}$; $\mathrm{Wei}^{7,8}$; Merigo et al. ${ }^{9}$ ).

Herrera et al. proposed 2-tuple linguistic representation model, which composed by a linguistic term and a real number (Herrera and Martínez ${ }^{10-12}$ ). The 2-tuple linguistic model has exact characteristic in linguistic information processing. It avoided information distortion and losing which occur formerly in the linguistic information processing. In recent years, 2-tuple linguistic model has been widely used in decision making problems (Jiang et al. ${ }^{1}$; Herrera and Martínez $^{12}$; Herrera-Viedma et al. ${ }^{13}$; Liu and Jin ${ }^{14}$; Jiang and $\mathrm{Fan}^{15}$; Yang and $\mathrm{Chen}^{16}$; García et al. $^{17}$; Wei and Zhao ${ }^{18}$; Wei ${ }^{19}$; Wei and $\mathrm{Lin}^{20}$; Wei et al. $^{21}$; Wei ${ }^{22,23}$; Chang and Wen ${ }^{24}$; Zhang and $\mathrm{Fan}^{25}$; Wang and $\mathrm{Fan}^{26}$; Wang $^{27}$; Herrera et al. ${ }^{28}$; Espinilla et al. ${ }^{29}$; Martínez and Herrera $^{30}$; Rodríguez and Martínez ${ }^{31}$ ). Wei ${ }^{8}$ developed some new geometric aggregation operators: the extended 2-tuple weighted geometric (ET-WG) and the extended 2-tuple ordered weighted geometric (ETOWG) operator. Then, a MAGDM method is presented based on the ET-WG and ET-OWG operators. Herrera and Martínez ${ }^{10}$ developed 2-tuple arithmetic averaging (TAA) operator, 2-tuple weighted averaging (TWA) operator, 2-tuple ordered weighted averaging (TOWA) operator and extended 2-tuple weighted averaging (ETWA) operator. Herrera and Martinez ${ }^{12}$ proposed another method to solve the group decision making problem with multi-granularity linguistic information. They constructed linguistic hierarchy term sets and generalized transformation functions to unify the multigranularity linguistic information into the linguistic 2tuples. Jiang and $\operatorname{Fan}^{15}$ proposed the 2-tuple weighted geometric (TWG) operator and 2-tuple ordered weighted geometric (TOWG) operator. Wei ${ }^{19}$ utilized the maximizing deviation method to solve the 2-tuple linguistic MAGDM with incomplete attribute weight information. Wei and $\mathrm{Lin}^{20}$ and $\mathrm{Wei}^{22}$ developed grey relational analysis (GRA) MAGDM methods based on 2-tuple linguistic information. $\mathrm{Xu}$ et al. ${ }^{21}$ adopted the virtual linguistic label to replace 2-tuple linguistic variable and proposed the linguistic power average operators and the uncertain linguistic power average operators. $\mathrm{Wei}^{23}$ developed three new aggregation operators: generalized 2-tuple weighted average (G2TWA) operator, generalized 2-tuple ordered weighted average (G-2TOWA) operator and induced generalized 2-tuple ordered weighted average (IG-2TOWA) operator. Chang and $\mathrm{Wen}^{24}$ proposed a novel technique combining 2-tuple and the Ordered Weighted Averaging (OWA) operator for prioritization of failures in a product design failure mode and effect analysis. Zhang and $\mathrm{Fan}^{25}$ proposed the extended 2-tuple ordered weighted averaging (ET-OWA) operator. Wang and Fan $^{26}$ proposed a TOPSIS method for solving MAGDM problems with 2-tuple linguistic assessment information. Wang $^{27}$ presented a 2-tuple fuzzy linguistic evaluation model for selecting appropriate agile manufacturing system in relation to MC production. Herrera et al. ${ }^{28}$ developed a fuzzy linguistic methodology to deal with unbalanced linguistic term sets.

Most of the proposals for solving MAGDM problems with 2-tuple linguistic information found in literature did not consider the importance degrees of different experts. However, the experts have their different cultural, educational backgrounds, experience and knowledge, and expertise related with the problem domain. Generally speaking, different experts act as different roles in the decision process. Some experts may assign unduly high or unduly low uncertain preference values to their preferred or repugnant objects. In order to relieve the influence of these unfair arguments on the decision results and reflect the importance degrees of all the experts, it is necessary to pay attention to the different importance degrees of different experts in the real-life MAGDM problems. Therefore, this paper develops some new hybrid geometric aggregation operators with 2-tuple linguistic information and proposes a new method for MAGDM problems with 2-tuple linguistic assessments. The motivation of this paper is based on the following facts:

(i) The existing aggregation operators with 2tuple linguistic information are mainly focused on the weighted arithmetic (geometric) average and the ordered weighted arithmetic (geometric) average 
operators. There has no investigation about the hybrid aggregation operators with 2-tuple linguistic information.

(ii) The hybrid aggregation operators can reflect the important degrees of both the given 2-tuples and the ordered positions of the 2-tuples. They are usually used to integrate the individual overall preference values of alternatives into the collective ones of alternatives. To do so, each individual overall preference value should first be weighted by using the corresponding expert weight, which can sufficiently reflect the importance degrees of different experts.

(iii) $\mathrm{Wei}^{8}$ only considered that the weight information of attributes and experts is in the form of the linguistic variables. The MAGDM method of $\mathrm{Wei}^{8}$ can not deal with the case that the weight information of attributes and experts takes the form of the 2-tuples. However, this case may appear in some real-life decision problems (see Section 5). These new hybrid geometric aggregation operators with 2-tuple linguistic information proposed in this paper can effectively overcome this drawback.

(iv) The proposed method in this paper is more reasonable and flexible than the existing ones and can be applicable to real-life decision problems in many areas such as risk investment, performance evaluation of military system, engineering management, supply chain, and so on.

The rest of the paper is arranged as follows. Section 2 introduces the notions for 2-tuple linguistic information, gives the operation laws and analyzes the properties of the operation laws. Section 3 presents the existing 2-tuple linguistic geometric aggregation operators and proposes some new hybrid geometric aggregation operators with 2-tuple linguistic information. Section 4 constructs the MAGDM model with 2-tuple linguistic assessments and proposes the corresponding decision method. A real application to evaluating university faculty for tenure and promotion example is given in Section 5. The comparison analysis with other method is conducted in Section 6 . Concluding remark is made in Section 7.

\section{2-tuple linguistic information}

In this section, some related notions for 2-tuple linguistic information are listed, then the operation laws and properties for 2-tuple linguistic information are investigated

\subsection{2-tuple linguistic information}

Definition 1. Let $S=\left\{s_{0}, s_{1}, s_{2}, \cdots, s_{t-1}\right\}$ be a finite and totally ordered discrete linguistic term set with odd cardinality, where $S_{i}$ represents a possible value for a linguistic variable. $\beta \in[0, t-1]$ is a number value representing the aggregation result of linguistic symbolic. Then the function $\Delta$ used to obtain the 2tuple linguistic information equivalent to $\beta$ is defined as:

$$
\begin{gathered}
\Delta:[0, t-1] \rightarrow S \times[-0.5,0.5) \\
\beta \rightarrow \Delta(\beta)=\left(s_{i}, \alpha\right)
\end{gathered}
$$

where $i=\operatorname{round}(\beta), \alpha=\beta-i, \alpha \in[-0.5,0.5)$, $\operatorname{round}(\cdot)$ is the usual round operation. $s_{i}$ has the closest index label to $\beta$ and $\alpha$ is the value of the symbolic translation (Herrera and Martínez ${ }^{10-12}$; Herrera et $\mathrm{al}^{4}$ ).

Definition 2. Let $S=\left\{s_{0}, s_{1}, s_{2}, \cdots, s_{t-1}\right\}$ be a linguistic term set and $\left(s_{i}, \alpha\right)$ be a linguistic 2-tuple. There is always a function $\Delta^{-1}$, such that, from a 2-tuple it returns its equivalent numerical value $\beta \in[0, t] \subset R$, which is (Herrera and Martínez ${ }^{10-12}$; Herrera et al. ${ }^{4}$ )

$$
\begin{gathered}
\Delta^{-1}: S \times[-0.5,0.5) \mapsto[0, t-1] \\
\Delta^{-1}\left(s_{i}, \alpha\right)=i+\alpha=\beta .
\end{gathered}
$$

From Definitions 1 and 2, we can conclude that the conversion of a linguistic term into a linguistic 2-tuple consists of adding a value 0 as symbolic translation:

$$
\Delta\left(s_{i}\right)=\left(s_{i}, 0\right) \text {. }
$$

Definition 3. Let $\left(s_{k}, \alpha_{k}\right)$ and $\left(s_{l}, \alpha_{l}\right)$ be two 2-tuples, they should have the following properties (Herrera and Martínez $^{10-12}$; Herrera et al. ${ }^{4}$ ):

1) If $k<l$, then $\left(s_{k}, \alpha_{k}\right)$ is smaller than $\left(s_{l}, \alpha_{l}\right)$, denoted by $\left(s_{k}, \alpha_{k}\right)<\left(s_{l}, \alpha_{l}\right)$;

2) If $k=l$, then

a) if $\alpha_{k}=\alpha_{l}$, then $\left(s_{k}, \alpha_{k}\right)$ and $\left(s_{l}, \alpha_{l}\right)$ represent the same information, denoted by $\left(s_{k}, \alpha_{k}\right)=\left(s_{l}, \alpha_{l}\right)$;

b) if $\alpha_{k}<\alpha_{l}$, then $\left(s_{k}, \alpha_{k}\right)<\left(s_{l}, \alpha_{l}\right)$;

c) If $\alpha_{k}>\alpha_{l}$, then $\left(s_{k}, \alpha_{k}\right)$ is bigger than $\left(s_{l}, \alpha_{l}\right)$, denoted by $\left(s_{k}, \alpha_{k}\right)>\left(s_{l}, \alpha_{l}\right)$.

\subsection{Operation laws and properties for 2-tuple linguistic information}

Definition 4. Let $\left(s_{k}, \alpha_{k}\right)$ and $\left(s_{l}, \alpha_{l}\right)$ be two 2-tuples and $\lambda \geq 0$. Then the operation laws for 2-tuples are defined as follows:

$$
\begin{aligned}
\text { (i) }\left(s_{k}, \alpha_{k}\right) \oplus\left(s_{l}, \alpha_{l}\right) & \left\{\begin{array}{l}
\Delta\left(\Delta^{-1}\left(s_{k}, \alpha_{k}\right)+\Delta^{-1}\left(s_{l}, \alpha_{l}\right)\right), \text { if } \Delta^{-1}\left(s_{k}, \alpha_{k}\right)+\Delta^{-1}\left(s_{l}, \alpha_{l}\right) \leq t-1 \\
\left(s_{t-1}, 0\right), \text { if } \Delta^{-1}\left(s_{k}, \alpha_{k}\right)+\Delta^{-1}\left(s_{l}, \alpha_{l}\right)>t-1
\end{array}\right.
\end{aligned}
$$


(ii) $\left(s_{k}, \alpha_{k}\right) \otimes\left(s_{l}, \alpha_{l}\right)$

$=\left\{\begin{array}{l}\Delta\left(\Delta^{-1}\left(s_{k}, \alpha_{k}\right) \Delta^{-1}\left(s_{l}, \alpha_{l}\right)\right), \text { if } \Delta^{-1}\left(s_{k}, \alpha_{k}\right) \Delta^{-1}\left(s_{l}, \alpha_{l}\right) \leq t-1 \\ \left(s_{t-1}, 0\right), \text { if } \Delta^{-1}\left(s_{k}, \alpha_{k}\right) \Delta^{-1}\left(s_{l}, \alpha_{l}\right)>t-1\end{array} ;\right.$

(iii) $\lambda\left(s_{k}, \alpha_{k}\right)$

$$
=\left\{\begin{array}{l}
\Delta\left(\lambda \Delta^{-1}\left(s_{k}, \alpha_{k}\right)\right), \text { if } \lambda \Delta^{-1}\left(s_{k}, \alpha_{k}\right) \leq t-1 \\
\left(s_{t-1}, 0\right), \text { if } \lambda \Delta^{-1}\left(s_{k}, \alpha_{k}\right)>t-1
\end{array} ;\right.
$$

(iv) $\left(s_{k}, \alpha_{k}\right)^{\lambda}$

$$
=\left\{\begin{array}{l}
\Delta\left(\left(\Delta^{-1}\left(s_{k}, \alpha_{k}\right)\right)^{\lambda}\right), \text { if }\left(\Delta^{-1}\left(s_{k}, \alpha_{k}\right)\right)^{\lambda} \leq t-1 \\
\left(s_{t-1}, 0\right), \text { if }\left(\Delta^{-1}\left(s_{k}, \alpha_{k}\right)\right)^{\lambda}>t-1
\end{array}\right.
$$

(v) $\left(s_{k}, \alpha_{k}\right)^{\left(s_{l}, \alpha_{l}\right)}$

$$
=\left\{\begin{array}{l}
\Delta\left(\left(\Delta^{-1}\left(s_{k}, \alpha_{k}\right)\right)^{\Delta^{-1}\left(s_{l}, \alpha_{l}\right)}\right), \text { if }\left(\Delta^{-1}\left(s_{k}, \alpha_{k}\right)\right)^{\Delta^{-1}\left(s_{l}, \alpha_{l}\right)} \leq t-1 \\
\left(s_{t-1}, 0\right), \text { if }\left(\Delta^{-1}\left(s_{k}, \alpha_{k}\right)\right)^{\Delta^{-1}\left(s_{l}, \alpha_{l}\right)}>t-1
\end{array} .\right.
$$

It should be noted that if the 2-tuple linguistic information comes from different linguistic term sets (i.e. multi-granularity linguistic information), they have to be converted into the fuzzy sets defined in the basic linguistic term set by means of a transformation function (Herrera, et $\mathrm{al}^{32}$ ), then they can be operated using the above operation laws.

If $\Delta^{-1}\left(s_{k}, \alpha_{k}\right)+\Delta^{-1}\left(s_{l}, \alpha_{l}\right)>t-1$, the addition for $\left(s_{k}, \alpha_{k}\right)$ and $\left(s_{l}, \alpha_{l}\right)$ may be considered as the maximum 2-tuple $\left(s_{t-1}, 0\right)$ on the linguistic term set $S$. The other operations can be interpreted analogously.

Obviously, Definition 4 can assure that the operation results regarding 2-tuples and linguistic terms must be in $[0, t-1]$, which is accordance with the CWW scheme (Rodríguez and Martínez ${ }^{31}$ ).

As far as we know, however, there is less investigation on the operation laws of 2-tuples. Definition 4 gives the operation laws of 2-tuples, which can be used to directly compute for 2-tuple linguistic information. Definition 4 is an interesting and valuable work for 2-tuples although there maybe lose little information under some situations. How to define more reasonable operation laws of 2-tuples will be further researched in the future.

In the following, suppose that a given linguistic term set is $S=\left\{s_{0}, s_{1}, s_{2}, \cdots, s_{8}\right\}$, we give some examples to illustrate the above Definition 4.

Example 1. $\left(s_{1}, 0.1\right) \oplus\left(s_{3}, 0.2\right)=\Delta\left(\Delta^{-1}\left(s_{1}, 0.1\right)+\Delta^{-1}\left(s_{3}, 0.2\right)\right)$

$$
=\Delta(4.3)=\left(s_{4}, 0.3\right) \text {; }
$$

$$
\left(s_{2}, 0.3\right) \oplus\left(s_{7}, 0.2\right)=\left(s_{8}, 0\right) .
$$

Example 2. $\left(s_{1}, 0.1\right) \otimes\left(s_{3}, 0.2\right)=\Delta\left(\Delta^{-1}\left(s_{1}, 0.1\right) \cdot \Delta^{-1}\left(s_{3}, 0.2\right)\right)$

$$
=\Delta(3.52)=\left(s_{4},-0.48\right) \text {; }
$$

$$
\left(s_{2}, 0.1\right) \otimes\left(s_{4}, 0.3\right)=\left(s_{8}, 0\right) \text {. }
$$

Example 3. $0.6\left(s_{2}, 0.3\right)=\Delta\left(0.6 \Delta^{-1}\left(s_{2}, 0.3\right)\right)$

$$
\begin{aligned}
=\Delta(1.38) & =\left(s_{1}, 0.38\right) ; \\
& \left.2\left(s_{4}, 0.2\right)=\left(s_{8}, 0\right)\right) .
\end{aligned}
$$

Example 4. $\left(s_{2}, 0.3\right)^{0.5}=\Delta\left(\left(\Delta^{-1}\left(s_{2}, 0.3\right)\right)^{0.5}\right)=\Delta\left(2.3^{0.5}\right)$

$$
\begin{array}{r}
=\Delta(1.5166)=\left(s_{2},-0.4834\right) ; \\
\left.\left(s_{4}, 0.2\right)^{2}=\left(s_{8}, 0\right)\right) .
\end{array}
$$

Example 5. $\left(s_{1}, 0.1\right)^{\left(s_{3}, 0.2\right)}=\Delta\left(\left(\Delta^{-1}\left(s_{1}, 0.1\right)\right)^{\Delta^{-1}\left(s_{3}, 0.2\right)}\right)$

$$
\begin{gathered}
=\Delta\left(1.1^{3.2}\right)=\Delta(1.3566)=\left(s_{1}, 0.3566\right) ; \\
\left(s_{3}, 0.2\right)^{\left(s_{4}, 0.4\right)}=\left(s_{8}, 0\right) .
\end{gathered}
$$

From Definition 4 , the following properties are proven:

1) $\left(s_{k}, \alpha_{k}\right) \oplus\left(s_{l}, \alpha_{l}\right)=\left(s_{l}, \alpha_{l}\right) \oplus\left(s_{k}, \alpha_{k}\right)$;

2) $\left(s_{k}, \alpha_{k}\right) \otimes\left(s_{l}, \alpha_{l}\right)=\left(s_{l}, \alpha_{l}\right) \otimes\left(s_{k}, \alpha_{k}\right)$;

3) $\lambda\left(\left(s_{k}, \alpha_{k}\right) \oplus\left(s_{l}, \alpha_{l}\right)\right)=\lambda\left(s_{k}, \alpha_{k}\right) \oplus \lambda\left(s_{l}, \alpha_{l}\right)$;

4) $\left(\left(s_{k}, \alpha_{k}\right)^{\lambda}\right)^{k}=\left(s_{k}, \alpha_{k}\right)^{\lambda k}$, $\left(s_{k}, \alpha_{k}\right)^{\lambda} \otimes\left(s_{k}, \alpha_{k}\right)^{k}=\left(s_{k}, \alpha_{k}\right)^{\lambda+k}, k \geq 0 ;$

5) For any $\left(s_{i}, \alpha_{i}\right)$, there have

$$
\begin{aligned}
& {\left[\left(s_{k}, \alpha_{k}\right) \oplus\left(s_{l}, \alpha_{l}\right)\right] \otimes\left(s_{i}, \alpha_{i}\right)} \\
& =\left[\left(s_{k}, \alpha_{k}\right) \otimes\left(s_{i}, \alpha_{i}\right)\right] \oplus\left[\left(s_{l}, \alpha_{l}\right) \otimes\left(s_{i}, \alpha_{i}\right)\right]
\end{aligned}
$$

and

$$
\begin{aligned}
& {\left[\left(s_{k}, \alpha_{k}\right) \otimes\left(s_{l}, \alpha_{l}\right)\right] \otimes\left(s_{i}, \alpha_{i}\right) } \\
= & \left(s_{k}, \alpha_{k}\right) \otimes\left[\left(s_{l}, \alpha_{l}\right) \otimes\left(s_{i}, \alpha_{i}\right)\right] .
\end{aligned}
$$

\section{Some geometric aggregation operators with 2- tuple linguistic information}

In this section, we first present the existing 2-tuple linguistic geometric aggregation operators, and then propose some new hybrid geometric aggregation operators with 2-tuple linguistic information.

\subsection{The existing 2-tuple linguistic geometric aggregation operators}

Based on Definitions 2 and 3, the existing 2-tuple linguistic geometric aggregation operators are presented in this subsection. For convenience, let $T$ be the set composed of all 2-tuples.

Definition 5. Let $x=\left\{\left(r_{1}, a_{1}\right),\left(r_{2}, a_{2}\right), \cdots,\left(r_{n}, a_{n}\right)\right\}$ be a set of 2-tuples, and $\boldsymbol{w}=\left(w_{1}, w_{2}, \cdots, w_{n}\right)^{\mathrm{T}}$ be the weighting vector of 2-tuples $\left(r_{j}, a_{j}\right) \quad(j=1,2, \cdots, n)$, satisfying that $0 \leq w_{j} \leq 1 \quad(j=1,2, \cdots, n)$ and $\sum_{j=1}^{n} w_{j}=1$. The 2-tuple weighted geometric (TWG) average operator is defined as (Jiang and Fan ${ }^{15}$ )

$\operatorname{TWG}_{w}\left(\left(r_{1}, a_{1}\right),\left(r_{2}, a_{2}\right), \cdots,\left(r_{n}, a_{n}\right)\right)=\Delta\left(\prod_{j=1}^{n} \Delta^{-1}\left(r_{j}, a_{j}\right)^{w_{j}}\right)$ 
Lemma 1. Let $a_{j}>0, w_{j}>0(j=1,2, \cdots, n)$ and $\sum_{j=1}^{n} w_{j}=1$, then

$$
\prod_{j=1}^{n}\left(a_{j}\right)^{w_{j}} \leq \sum_{j=1}^{n} w_{j} a_{j},
$$

with equality if and only if $a_{1}=a_{2}=\cdots=a_{n}$ (Torra and Narukawa ${ }^{33}$ ).

Theorem 1. In Definition 5, the argument of delta in Eq.

(4), $\prod_{j=1}^{n} \Delta^{-1}\left(r_{j}, a_{j}\right)^{w_{j}}$, is defined in $[0, t-1]$.

Proof. By Definition 2, we know that $\Delta^{-1}: S \times[-0.5,0.5) \mapsto[0, t-1] \quad$. Thus, $0 \leq \Delta^{-1}\left(r_{j}, a_{j}\right) \leq t-1 \quad(j=1,2, \cdots, n)$.

Since the weighted vector $\boldsymbol{w}=\left(w_{1}, w_{2}, \cdots, w_{n}\right)^{\mathrm{T}}$ satisfies that $0 \leq w_{j} \leq 1 \quad(j=1,2, \cdots, n)$ and $\sum_{j=1}^{n} w_{j}=1$, it yields by Lemma 1 that

$$
0 \leq \prod_{j=1}^{n} \Delta^{-1}\left(r_{j}, a_{j}\right)^{w_{j}} \leq \sum_{j=1}^{n} w_{j} \Delta^{-1}\left(r_{j}, a_{j}\right) \leq \sum_{j=1}^{n} w_{j}(t-1)=(t-1) .
$$

Therefore, $\prod_{j=1}^{n} \Delta^{-1}\left(r_{j}, a_{j}\right)^{w_{j}} \in[0, t-1]$ and the proof of Theorem 1 is completed.

Definition 6. Let $x=\left\{\left(r_{1}, a_{1}\right),\left(r_{2}, a_{2}\right), \cdots,\left(r_{n}, a_{n}\right)\right\}$ be a set of 2-tuples. The 2-tuple ordered weighted geometric (TOWG) average operator of dimension $n$ is a mapping TOWG : $T^{n} \rightarrow T$ so that

$$
\begin{aligned}
& \operatorname{TOWG}_{w}\left(\left(r_{1}, a_{1}\right),\left(r_{2}, a_{2}\right), \cdots,\left(r_{n}, a_{n}\right)\right) \\
& =\Delta\left(\prod_{j=1}^{n} \Delta^{-1}\left(r_{\sigma(j)}, a_{\sigma(j)}\right)^{w_{j}}\right) .
\end{aligned}
$$

where $\boldsymbol{w}=\left(w_{1}, w_{2}, \cdots, w_{n}\right)^{\mathrm{T}}$ is the weighted vector correlating with TOWG, satisfying that $0 \leq w_{j} \leq 1$ $(j=1,2, \cdots, n)$ and $\sum_{j=1}^{n} w_{j}=1 .\left(\sigma_{(1)}, \sigma_{(2)}, \cdots, \sigma_{(n)}\right)$ is a permutation of $(1,2, \cdots, n)$ such that $\left(r_{\sigma(j-1)}, a_{\sigma(j-1)}\right) \geq\left(r_{\sigma(j)}, a_{\sigma(j)}\right)$ for any $j\left(\right.$ Jiang and $\left.\operatorname{Fan}^{15}\right)$. Remark 1. In Definition 6, since the weighted vector $\boldsymbol{w}=\left(w_{1}, w_{2}, \cdots, w_{n}\right)^{\mathrm{T}} \quad$ satisfies that $\quad 0 \leq w_{j} \leq 1$ $(j=1,2, \cdots, n)$ and $\sum_{j=1}^{n} w_{j}=1$, the argument of delta in Eq. (5), $\prod_{j=1}^{n} \Delta^{-1}\left(r_{\sigma(j)}, a_{\sigma(j)}\right)^{w_{j}}$, is also defined in $[0, t-1]$, which can be proven by the similar way to Theorem 1 .
Definition 7. Let $x=\left\{\left(r_{1}, a_{1}\right),\left(r_{2}, a_{2}\right), \cdots,\left(r_{n}, a_{n}\right)\right\}$ be a set of 2-tuples, and $\boldsymbol{C}=\left(\left(c_{1}, b_{1}\right),\left(c_{2}, b_{2}\right), \cdots,\left(c_{n}, b_{n}\right)\right)^{\mathrm{T}}$ be the linguistic weighting vector of 2-tuples $\left(r_{j}, a_{j}\right)$ $(j=1,2 \cdots, n)$. The extended 2-tuple weighted geometric (ET-WG) average operator is defined as $\left(\mathrm{Wei}^{8}\right)$

$$
\begin{aligned}
& \text { ET-WG }{ }_{C}\left(\left(r_{1}, a_{1}\right),\left(r_{2}, a_{2}\right), \cdots,\left(r_{n}, a_{n}\right)\right) \\
& =\Delta\left(\prod_{j=1}^{n}\left(\Delta^{-1}\left(r_{j}, a_{j}\right)\right)^{\frac{\Delta^{-1}\left(c_{j}, b_{j}\right)}{\sum_{j=1}^{n} \Delta^{-1}\left(c_{j}, b_{j}\right)}}\right) .
\end{aligned}
$$

Remark 2. In Definition 7, since the power index $\frac{\Delta^{-1}\left(c_{j}, b_{j}\right)}{\sum_{j=1}^{n} \Delta^{-1}\left(c_{j}, b_{j}\right)}$ satisfies that $0 \leq \frac{\Delta^{-1}\left(c_{j}, b_{j}\right)}{\sum_{j=1}^{n} \Delta^{-1}\left(c_{j}, b_{j}\right)} \leq 1 \quad(j=1,2, \cdots, n)$ and $\sum_{j=1}^{n} \frac{\Delta^{-1}\left(c_{j}, b_{j}\right)}{\sum_{j=1}^{n} \Delta^{-1}\left(c_{j}, b_{j}\right)}=1$, the argument of delta in Eq (6), $\prod_{j=1}^{n}\left(\Delta^{-1}\left(r_{j}, a_{j}\right)\right)^{\frac{\Delta^{-1}\left(c_{j}, b_{j}\right)}{\sum_{j=1}^{n} \Delta^{-1}\left(c_{j}, b_{j}\right)}}$, is defined in $[0, t-1]$, which can be easily proven by the similar way to Theorem 1 .

Definition 8. Let $x=\left\{\left(r_{1}, a_{1}\right),\left(r_{2}, a_{2}\right), \cdots,\left(r_{n}, a_{n}\right)\right\}$ be a set of 2-tuples. The extended 2-tuple ordered weighted geometric (ET-OWG) average operator of dimension $n$ is a mapping ET-OWG: $T^{n} \rightarrow T$ so that

$$
\begin{aligned}
& \text { ET-OWG }_{L}\left(\left(r_{1}, a_{1}\right),\left(r_{2}, a_{2}\right), \cdots,\left(r_{n}, a_{n}\right)\right) \\
& =\Delta\left(\prod_{j=1}^{n}\left(\Delta^{-1}\left(r_{\sigma(j)}, a_{\sigma(j)}\right)\right)^{\frac{\Delta^{-1}\left(l_{j}, \eta_{j}\right)}{\sum_{j=1}^{n} \Delta^{-1}\left(l_{j}, \eta_{j}\right)}}\right),
\end{aligned}
$$

where $\boldsymbol{L}=\left(\left(l_{1}, \eta_{1}\right),\left(l_{2}, \eta_{2}\right), \cdots,\left(l_{n}, \eta_{n}\right)\right)^{\mathrm{T}}$ is the linguistic weighted vector correlating with ET-OWG , $\left(\sigma_{(1)}, \sigma_{(2)}, \cdots, \sigma_{(n)}\right)$ is a permutation of $(1,2, \cdots, n)$ such that $\left(r_{\sigma(j-1)}, a_{\sigma(j-1)}\right) \geq\left(r_{\sigma(j)}, a_{\sigma(j)}\right)$ for any $j\left(\mathrm{Wei}^{8}\right)$.

Remark 3. In Definition 8, since the power index $\frac{\Delta^{-1}\left(l_{j}, \eta_{j}\right)}{\sum_{j=1}^{n} \Delta^{-1}\left(l_{j}, \eta_{j}\right)}$ satisfies that $0 \leq \frac{\Delta^{-1}\left(l_{j}, \eta_{j}\right)}{\sum_{j=1}^{n} \Delta^{-1}\left(l_{j}, \eta_{j}\right)} \leq 1 \quad(j=1,2, \cdots, n)$ and $\sum_{j=1}^{n} \frac{\Delta^{-1}\left(l_{j}, \eta_{j}\right)}{\sum_{j=1}^{n} \Delta^{-1}\left(l_{j}, \eta_{j}\right)}=1$, the argument of delta in Eq (7), $\prod_{j=1}^{n}\left(\Delta^{-1}\left(r_{\sigma(j)}, a_{\sigma(j)}\right)\right)^{\frac{\Delta^{-1}\left(l_{j}, \eta_{j}\right)}{\sum_{j=1}^{n} \Delta^{-1}\left(l_{j}, \eta_{j}\right)}}$, is also defined in $[0, t-1]$, which can be easily proven by the similar way to Theorem 1. 


\subsection{The new hybrid geometric aggregation operators with 2-tuple linguistic information}

It can be seen from Definitions 7 and 8 that the ET-WG operator weights the 2-tuple linguistic arguments while the ET-OWG operator weights the ordered positions of the 2-tuple linguistic arguments instead of weighting the arguments themselves. Therefore, weights represent different aspects in both the ET-WG and ET-OWG operators. However, both the operators consider only one of them. To solve this drawback, based on Definitions 2, 3 and 4, some new hybrid geometric aggregation operators with 2-tuple linguistic information are developed in the following.

Definition 9. Let $x=\left\{\left(r_{1}, a_{1}\right),\left(r_{2}, a_{2}\right), \cdots,\left(r_{n}, a_{n}\right)\right\}$ be a set of 2-tuples. If THWG : $T^{n} \rightarrow T$ so that

$$
\begin{aligned}
& \text { THWG }_{w, \omega}\left(\left(r_{1}, a_{1}\right),\left(r_{2}, a_{2}\right), \cdots,\left(r_{n}, a_{n}\right)\right) \\
& =\Delta\left(\prod_{j=1}^{n}\left(\Delta^{-1}\left(r_{\sigma(j)}^{\prime}, a_{\sigma(j)}^{\prime}\right)\right)^{w_{j}}\right),
\end{aligned}
$$

where $\boldsymbol{w}=\left(w_{1}, w_{2}, \cdots, w_{n}\right)^{\mathrm{T}}$ is the weighted vector correlating with THWG, satisfying that $0 \leq w_{j} \leq 1$ $(j=1,2 \cdots, n)$ and $\sum_{j=1}^{n} w_{j}=1 .\left(r_{\sigma(j)}^{\prime}, a_{\sigma(j)}^{\prime}\right)$ is the $j$ th largest 2-tuple of 2-tuples $\left(r_{i}^{\prime}, a_{i}^{\prime}\right)(i=1,2, \cdots, n)$ with $\left(r_{i}^{\prime}, a_{i}^{\prime}\right)=\left(r_{i}, a_{i}\right)^{n \omega_{i}}, \omega=\left(\omega_{1}, \omega_{2}, \cdots, \omega_{n}\right)^{\mathrm{T}}$ is the weight vector of 2-tuples $\left(r_{j}, a_{j}\right) \quad(j=1,2 \cdots, n)$, satisfying that $0 \leq \omega_{j} \leq 1 \quad(j=1,2 \cdots, n)$ and $\sum_{j=1}^{n} \omega_{j}=1, n$ is the balancing coefficient (in this case, if $\omega=\left(\omega_{1}, \omega_{2}, \cdots, \omega_{n}\right)^{\mathrm{T}}$ goes to $\left(\frac{1}{n}, \frac{1}{n}, \cdots, \frac{1}{n}\right)^{\mathrm{T}} \quad$, then $\left(r_{i}^{\prime}, a_{i}^{\prime}\right)$ goes to $\left(r_{i}, a_{i}\right)$ $(i=1,2, \cdots, n))$. Then, the function THWG is called the 2-tuple hybrid weighted geometric average operator of dimension $n$.

Theorem 2. In Definition 9, the argument of delta in Eq. (8) , $\prod_{j=1}^{n}\left(\Delta^{-1}\left(r_{\sigma(j)}^{\prime}, a_{\sigma(j)}^{\prime}\right)\right)^{w_{j}}$, is defined in $[0, t-1]$.

Proof. According to (iv) of Definition 4, we have

$$
\begin{gathered}
\left(r_{i}^{\prime}, a_{i}^{\prime}\right)=\left(r_{i}, a_{i}\right)^{n \omega_{i}} \\
=\left\{\begin{array}{l}
\Delta\left(\left(\Delta^{-1}\left(r_{i}, a_{i}\right)\right)^{n \omega_{i}}\right), \text { if }\left(\Delta^{-1}\left(r_{i}, a_{i}\right)\right)^{n \omega_{i}} \leq t-1 \\
\left(s_{t-1}, 0\right), \text { if }\left(\Delta^{-1}\left(r_{i}, a_{i}\right)\right)^{n \omega_{i}}>t-1
\end{array} .\right.
\end{gathered}
$$

Hence, in Definition $9, \Delta^{-1}\left(r_{i}^{\prime}, a^{\prime}\right) \in[0, t-1]$ and thus $\Delta^{-1}\left(r_{\sigma(j)}^{\prime}, a_{\sigma(j)}^{\prime}\right) \in[0, t-1]$.

In addition, since the weighted vector $\boldsymbol{w}=\left(w_{1}, w_{2}, \cdots, w_{n}\right)^{\mathrm{T}} \quad$ satisfies $\quad$ that $\quad 0 \leq w_{j} \leq 1$ $(j=1,2, \cdots, n)$ and $\sum_{j=1}^{n} w_{j}=1$, it follows from Lemma 1 that

$$
\begin{aligned}
0 \leq \prod_{j=1}^{n}\left(\Delta^{-1}\left(r_{\sigma(j)}^{\prime}, a_{\sigma(j)}^{\prime}\right)\right)^{w_{j}} & \leq \sum_{j=1}^{n} w_{j} \Delta^{-1}\left(r_{\sigma(j)}^{\prime}, a_{\sigma(j)}^{\prime}\right) \\
\leq \sum_{j=1}^{n} w_{j}(t-1)= & t-1 .
\end{aligned}
$$

Namely, $\prod_{j=1}^{n}\left(\Delta^{-1}\left(r_{\sigma(j)}^{\prime}, a_{\sigma(j)}^{\prime}\right)\right)^{w_{j}}$ is defined in $[0, t-1]$.

Example 6. Assume that $\left(r_{1}, a_{1}\right)=\left(s_{1}, 0.1\right)$, $\left(r_{2}, a_{2}\right)=\left(s_{3}, 0.3\right),\left(r_{3}, a_{3}\right)=\left(s_{2}, 0.2\right),\left(r_{4}, a_{4}\right)=\left(s_{4}, 0.3\right)$, $\boldsymbol{w}=(0.2,0.3,0.3,0.2)^{\mathrm{T}}$ and $\boldsymbol{\omega}=(0.1,0.4,0.3,0.2)^{\mathrm{T}}$, then,

$$
\begin{gathered}
\left(r_{1}^{\prime}, a_{1}^{\prime}\right)=\left(s_{1}, 0.1\right)^{4 \times 0.1}=\left(s_{1}, 0.0389\right), \\
\left(r_{2}^{\prime}, a_{2}^{\prime}\right)=\left(s_{3}, 0.3\right)^{4 \times 0.4}=\left(s_{7},-0.245\right), \\
\left(r_{3}^{\prime}, a_{3}^{\prime}\right)=\left(s_{2}, 0.2\right)^{4 \times 0.3}=\left(s_{3},-0.4242\right)
\end{gathered}
$$

and

Therefore,

$$
\left(r_{4}^{\prime}, a_{4}^{\prime}\right)=\left(s_{4}, 0.3\right)^{4 \times 0.2}=\left(s_{3}, 0.212\right) .
$$

and

$$
\begin{gathered}
\left(r_{\sigma(1)}^{\prime}, a_{\sigma(1)}^{\prime}\right)=\left(s_{7},-0.245\right), \\
\left(r_{\sigma(2)}^{\prime}, a_{\sigma(2)}^{\prime}\right)=\left(s_{3}, 0.212\right), \\
\left(r_{\sigma(3)}^{\prime}, a_{\sigma(3)}^{\prime}\right)=\left(s_{3},-0.4242\right)
\end{gathered}
$$

$$
\left(r_{\sigma(4)}^{\prime}, a_{\sigma(4)}^{\prime}\right)=\left(s_{1}, 0.0389\right) \text {. }
$$

Thus,

$$
\begin{aligned}
& \operatorname{THWG}_{w, \omega}\left(\left(r_{1}, a_{1}\right),\left(r_{2}, a_{2}\right),\left(r_{3}, a_{3}\right),\left(r_{4}, a_{4}\right)\right) \\
& =\Delta\left(\prod_{j=1}^{4}\left(\Delta^{-1}\left(r_{\sigma(j)}^{\prime}, a_{\sigma(j)}^{\prime}\right)\right)^{w_{j}}\right)=\Delta(2.9980)=\left(s_{3},-0.002\right) .
\end{aligned}
$$

Theorem 3. The TOWG operator is a special case of the THWG operator.

Proof. Let $\quad \omega_{j}=\frac{1}{n} \quad(j=1,2, \cdots, n) \quad$, then $\left(r_{i}^{\prime}, a_{i}^{\prime}\right)=\left(r_{i}, a_{i}\right)^{n \omega_{i}}=\left(r_{i}, a_{i}\right) \quad(i=1,2, \cdots, n) \quad$. This completes the proof of Theorem 3 .

Theorem 4. The TWG operator is a special case of the THWG operator.

Proof. Let $w_{j}=\frac{1}{n}(j=1,2, \cdots, n)$, then

$$
\begin{aligned}
& \operatorname{THWG}_{w, \omega}\left(\left(r_{1}, a_{1}\right),\left(r_{2}, a_{2}\right), \cdots,\left(r_{n}, a_{n}\right)\right) \\
& =\Delta\left(\prod_{j=1}^{n}\left(\Delta^{-1}\left(r_{\sigma(j)}^{\prime}, a_{\sigma(j)}^{\prime}\right)\right)^{w_{j}}\right) \\
& =\Delta\left(\prod_{j=1}^{n}\left(\Delta^{-1}\left(r_{\sigma(j)}^{\prime}, a_{\sigma(j)}^{\prime}\right)\right)^{\frac{1}{n}}\right) \\
& =\Delta\left(\prod_{j=1}^{n}\left(\Delta^{-1}\left(\left(r_{i}, a_{i}\right)^{n \omega_{i}}\right)\right)^{\frac{1}{n}}\right)
\end{aligned}
$$




$$
\begin{aligned}
& =\Delta\left(\prod_{j=1}^{n}\left(\Delta^{-1}\left(r_{i}, a_{i}\right)\right)^{n \omega_{i} \frac{1}{n}}\right) \\
& =\Delta\left(\prod_{j=1}^{n}\left(\Delta^{-1}\left(r_{i}, a_{i}\right)\right)^{\omega_{i}}\right) \\
& =\operatorname{TWG}_{\omega}\left(\left(r_{1}, a_{1}\right),\left(r_{2}, a_{2}\right), \cdots,\left(r_{n}, a_{n}\right)\right),
\end{aligned}
$$

which completes the proof of Theorem 4.

From Theorems 3 and 4, we know that, the THWG operator first weights the given arguments, and then reorders the weighted arguments in descending order and weights these ordered arguments, and finally aggregates all the weighted arguments into a collective one. The THWG operator generalizes both the TWG and TOWG operators. The THWG operator reflects the important degrees of both the given 2-tuples and the ordered positions of the 2-tuples.

Definition 10. Let $x=\left\{\left(r_{1}, a_{1}\right),\left(r_{2}, a_{2}\right), \cdots,\left(r_{n}, a_{n}\right)\right\}$ be a set of 2-tuples. If T-HLWG $: T^{n} \rightarrow T$ so that

$$
\begin{aligned}
& \text { T-HLWG }{ }_{L, \omega}\left(\left(r_{1}, a_{1}\right),\left(r_{2}, a_{2}\right), \cdots,\left(r_{n}, a_{n}\right)\right) \\
& =\Delta\left(\prod_{j=1}^{n}\left(\Delta^{-1}\left(r_{\sigma(j)}^{\prime}, a_{\sigma(j)}^{\prime}\right)\right)^{\frac{\Delta^{-1}\left(l_{j}, \eta_{j}\right)}{\sum_{j=1}^{n} \Delta^{-1}\left(l_{j}, \eta_{j}\right)}}\right),
\end{aligned}
$$

where $\boldsymbol{L}=\left(\left(l_{1}, \eta_{1}\right),\left(l_{2}, \eta_{2}\right), \cdots,\left(l_{n}, \eta_{n}\right)\right)^{\mathrm{T}}$ is the linguistic weighted vector correlating with T-HLWG, $\left(r_{\sigma(j)}^{\prime}, a_{\sigma(j)}^{\prime}\right)$ is the $j$ th largest 2-tuple of 2-tuples $\left(r_{i}^{\prime}, a_{i}^{\prime}\right) \quad(i=1,2, \cdots, n) \quad$ with $\quad\left(r_{i}^{\prime}, a_{i}^{\prime}\right)=\left(r_{i}, a_{i}\right)^{n \omega_{i}}$, $\boldsymbol{\omega}=\left(\omega_{1}, \omega_{2}, \cdots, \omega_{n}\right)^{\mathrm{T}}$ is the weight vector of 2-tuples $\left(r_{j}, a_{j}\right)$ $(j=1,2, \cdots, n)$, satisfying that $0 \leq \omega_{j} \leq 1 \quad(j=1,2, \cdots, n)$ and $\sum_{j=1}^{n} \omega_{j}=1, n$ is the balancing coefficient (in this case, if $\omega=\left(\omega_{1}, \omega_{2}, \cdots, \omega_{n}\right)^{\mathrm{T}}$ goes to $\left(\frac{1}{n}, \frac{1}{n}, \cdots, \frac{1}{n}\right)^{\mathrm{T}}$, then $\left(r_{i}^{\prime}, a_{i}^{\prime}\right)$ goes to $\left.\left(r_{i}, a_{i}\right) \quad(i=1,2, \cdots, n)\right)$. Then, the function THLWG is called the 2-tuple hybrid linguistic weighted geometric average operator of dimension $n$.

Remark 4. According to (iv) of Definition 4,

$$
\begin{gathered}
\left(r_{i}^{\prime}, a_{i}^{\prime}\right)=\left(r_{i}, a_{i}\right)^{n \omega_{i}} \\
=\left\{\begin{array}{l}
\Delta\left(\left(\Delta^{-1}\left(r_{i}, a_{i}\right)\right)^{n \omega_{i}}\right), \text { if }\left(\Delta^{-1}\left(r_{i}, a_{i}\right)\right)^{n \omega_{i}} \leq t-1 \\
\left(s_{t-1}, 0\right), \text { if }\left(\Delta^{-1}\left(r_{i}, a_{i}\right)\right)^{n \omega_{i}}>t-1
\end{array} .\right.
\end{gathered}
$$

Hence, in Definition 10, $\Delta^{-1}\left(r_{\sigma(j)}^{\prime}, a_{\sigma(j)}^{\prime}\right) \in[0, t-1]$. Meanwhile, since the power index $\frac{\Delta^{-1}\left(l_{j}, \eta_{j}\right)}{\sum_{j=1}^{n} \Delta^{-1}\left(l_{j}, \eta_{j}\right)}$ satisfies that $0 \leq \frac{\Delta^{-1}\left(l_{j}, \eta_{j}\right)}{\sum_{j=1}^{n} \Delta^{-1}\left(l_{j}, \eta_{j}\right)} \leq 1(j=1,2, \cdots, n)$ and $\sum_{j=1}^{n} \frac{\Delta^{-1}\left(l_{j}, \eta_{j}\right)}{\sum_{j=1}^{n} \Delta^{-1}\left(l_{j}, \eta_{j}\right)}=1$, the argument of delta in Eq. (9) ,
$\prod_{j=1}^{n}\left(\Delta^{-1}\left(r_{\sigma(j)}^{\prime}, a_{\sigma(j)}^{\prime}\right)\right)^{\frac{\Delta^{-1}\left(l_{j}, \eta_{j}\right)}{\sum_{j=1}^{n} \Delta^{-1}\left(l_{j}, \eta_{j}\right)}}$, is defined in [0,t-1], which can be easily proven by the similar way to Theorem 2.

Example 7. Assume that

$$
\begin{aligned}
& \left(l_{1}, \eta_{1}\right)=\left(s_{3}, 0.4\right),\left(l_{2}, \eta_{2}\right)=\left(s_{2}, 0.2\right), \\
& \left(l_{3}, \eta_{3}\right)=\left(s_{1}, 0.1\right),\left(l_{4}, \eta_{4}\right)=\left(s_{5}, 0.2\right), \\
& \left(r_{1}, a_{1}\right)=\left(s_{1}, 0.1\right),\left(r_{2}, a_{2}\right)=\left(s_{3}, 0.3\right), \\
& \left(r_{3}, a_{3}\right)=\left(s_{2}, 0.2\right),\left(r_{4}, a_{4}\right)=\left(s_{4}, 0.3\right)
\end{aligned}
$$

and

$$
\omega=(0.1,0.4,0.3,0.2)^{\mathrm{T}} \text {, }
$$

then,

$$
\begin{gathered}
\left(r_{1}^{\prime}, a_{1}^{\prime}\right)=\left(s_{1}, 0.1\right)^{4 \times 0.1}=\left(s_{1}, 0.0389\right), \\
\left(r_{2}^{\prime}, a_{2}^{\prime}\right)=\left(s_{3}, 0.3\right)^{4 \times 0.4}=\left(s_{7},-0.245\right), \\
\left(r_{3}^{\prime}, a_{3}^{\prime}\right)=\left(s_{2}, 0.2\right)^{4 \times 0.3}=\left(s_{3},-0.4242\right), \\
\left(r_{4}^{\prime}, a_{4}^{\prime}\right)=\left(s_{4}, 0.3\right)^{4 \times 0.2}=\left(s_{3}, 0.212\right) .
\end{gathered}
$$

Therefore,

$$
\begin{gathered}
\left(r_{\sigma(1)}^{\prime}, a_{\sigma(1)}^{\prime}\right)=\left(s_{7},-0.245\right), \\
\left(r_{\sigma(2)}^{\prime}, a_{\sigma(2)}^{\prime}\right)=\left(s_{3}, 0.212\right), \\
\left(r_{\sigma(3)}^{\prime}, a_{\sigma(3)}^{\prime}\right)=\left(s_{3},-0.4242\right)
\end{gathered}
$$

and

$$
\left(r_{\sigma(4)}^{\prime}, a_{\sigma(4)}^{\prime}\right)=\left(s_{1}, 0.0389\right) \text {. }
$$

Thus,

$$
\begin{aligned}
& \text { T-HLWG }{ }_{L, \omega}\left(\left(r_{1}, a_{1}\right),\left(r_{2}, a_{2}\right),\left(r_{3}, a_{3}\right),\left(r_{4}, a_{4}\right)\right) \\
& =\Delta\left(\prod_{j=1}^{4}\left(\Delta^{-1}\left(r_{\sigma(j)}^{\prime}, a_{\sigma(j)}^{\prime}\right)\right)^{\frac{\Delta^{-1}\left(l_{j}, \eta_{j}\right)}{\sum_{j=1}^{4} \Delta^{-1}\left(l_{j}, \eta_{j}\right)}}\right) \\
& =\Delta(2.3765)=\left(s_{2}, 0.3765\right) .
\end{aligned}
$$

Theorem 5. The ET-OWG operator is a special case of the T-HLWG operator.

Proof. Let $\omega_{j}=\frac{1}{n} \quad(j=1,2, \cdots, n) \quad$, then $\left(r_{i}^{\prime}, a_{i}^{\prime}\right)=\left(r_{i}, a_{i}\right)^{n \omega_{i}}=\left(r_{i}, a_{i}\right) \quad, \quad(i=1,2, \cdots, n) \quad$. This completes the proof of Theorem 5 .

Definition 11. Let $x=\left\{\left(r_{1}, a_{1}\right),\left(r_{2}, a_{2}\right), \cdots,\left(r_{n}, a_{n}\right)\right\}$ be a set of 2-tuples. If ET-HLWG $: T^{n} \rightarrow T$ so that

$$
\begin{aligned}
& \text { ET-HLWG }_{L, C}\left(\left(r_{1}, a_{1}\right),\left(r_{2}, a_{2}\right), \cdots,\left(r_{n}, a_{n}\right)\right) \\
& =\Delta\left(\prod_{j=1}^{n}\left(\Delta^{-1}\left(r_{\sigma(j)}^{\prime}, a_{\sigma(j)}^{\prime}\right)\right)^{\frac{\Delta^{-1}\left(l_{j}, \eta_{j}\right)}{\sum_{j=1}^{n} \Delta^{-1}\left(l_{j}, \eta_{j}\right)}}\right),
\end{aligned}
$$

where $\boldsymbol{L}=\left(\left(l_{1}, \eta_{1}\right),\left(l_{2}, \eta_{2}\right), \cdots,\left(l_{n}, \eta_{n}\right)\right)^{\mathrm{T}}$ is the linguistic weighted vector correlating with ET-HLWG. $\left(r_{\sigma(j)}^{\prime}, a_{\sigma(j)}^{\prime}\right)$ is the $j$ th largest 2-tuple of 2-tuples 
$\left(r_{i}^{\prime}, a_{i}^{\prime}\right) \quad(i=1,2, \cdots, n) \quad$ with $\quad\left(r_{i}^{\prime}, a_{i}^{\prime}\right)=\left(r_{i}, a_{i}\right)^{n\left(c_{i}, b_{i}\right)}$, $\boldsymbol{C}=\left(\left(c_{1}, b_{1}\right),\left(c_{2}, b_{2}\right), \cdots,\left(c_{n}, b_{n}\right)\right)^{\mathrm{T}}$ is the linguistic weight vector of 2-tuples $\left(r_{j}, a_{j}\right) \quad(j=1,2, \cdots, n), n$ is the balancing coefficient. Then, the function ET-HLWG is called the extended 2-tuple hybrid linguistic weighted geometric average operator of dimension $n$.

Theorem 6. In Definition 11, the argument of delta in Eq. (10), $\prod_{j=1}^{n}\left(\Delta^{-1}\left(r_{\sigma(j)}^{\prime}, a_{\sigma(j)}^{\prime}\right)\right)^{\frac{\Delta^{-1}\left(l_{j}, \eta_{j}\right)}{\sum_{j=1}^{n} \Delta^{-1}\left(l_{j}, \eta_{j}\right)}}$, is defined in $[0, t-1]$.

Proof. According to (iii) of Definition 4, we get that

$$
n\left(c_{i}, b_{i}\right)=\left\{\begin{array}{l}
\Delta\left(n \Delta^{-1}\left(c_{i}, b_{i}\right)\right), \text { if } n \Delta^{-1}\left(c_{i}, b_{i}\right) \leq t-1 \\
\left(s_{t-1}, 0\right), \text { if } n \Delta^{-1}\left(c_{i}, b_{i}\right)>t-1
\end{array} .\right.
$$

According to (v) of Definition 4,

$$
\begin{gathered}
\left(r_{i}^{\prime}, a_{i}^{\prime}\right)=\left(r_{i}, a_{i}\right)^{n\left(c_{i}, b_{i}\right)} \\
=\left\{\begin{array}{l}
\Delta\left(\left(\Delta^{-1}\left(r_{i}, a_{i}\right)\right)^{n \Delta^{-1}\left(c_{i}, b_{i}\right)}\right), \text { if }\left(\Delta^{-1}\left(r_{i}, a_{i}\right)\right)^{n \Delta^{-1}\left(c_{i}, b_{i}\right)} \leq t-1 \\
\left(s_{t-1}, 0\right), \text { if }\left(\Delta^{-1}\left(r_{i}, a_{i}\right)\right)^{n \Delta^{-1}\left(c_{i}, b_{i}\right)}>t-1
\end{array}\right.
\end{gathered}
$$

Hence, in Definition $11, \Delta^{-1}\left(r_{i}^{\prime}, a_{i}^{\prime}\right) \in[0, t-1]$ and thus $\Delta^{-1}\left(r_{\sigma(j)}^{\prime}, a_{\sigma(j)}^{\prime}\right) \in[0, t-1]$.

Moreover, since the power index $\frac{\Delta^{-1}\left(l_{j}, \eta_{j}\right)}{\sum_{j=1}^{n} \Delta^{-1}\left(l_{j}, \eta_{j}\right)}$ satisfies that $\quad 0 \leq \frac{\Delta^{-1}\left(l_{j}, \eta_{j}\right)}{\sum_{j=1}^{n} \Delta^{-1}\left(l_{j}, \eta_{j}\right)} \leq 1 \quad(j=1,2, \cdots, n) \quad$ and $\sum_{j=1}^{n} \frac{\Delta^{-1}\left(l_{j}, \eta_{j}\right)}{\sum_{j=1}^{n} \Delta^{-1}\left(l_{j}, \eta_{j}\right)}=1$, it yields by Lemma 1 that

$$
\begin{aligned}
& 0 \leq \prod_{j=1}^{n}\left(\Delta^{-1}\left(r_{\sigma(j)}^{\prime}, a_{\sigma(j)}^{\prime}\right)\right)^{\frac{\Delta_{j=1}^{-1}\left(l_{j}, \eta_{j}\right)}{\sum_{j=1}^{n} \Delta^{-1}\left(l_{j}, \eta_{j}\right)}} \\
& \leq \sum_{j=1}^{n} \frac{\Delta^{-1}\left(l_{j}, \eta_{j}\right)}{\sum_{j=1}^{n} \Delta^{-1}\left(l_{j}, \eta_{j}\right)} \Delta^{-1}\left(r_{\sigma(j)}^{\prime}, a_{\sigma(j)}^{\prime}\right) \\
& \leq \sum_{j=1}^{n} \frac{\Delta^{-1}\left(l_{j}, \eta_{j}\right)}{\sum_{j=1}^{n} \Delta^{-1}\left(l_{j}, \eta_{j}\right)}(t-1)=t-1 .
\end{aligned}
$$

Therefore, the argument of delta in Eq. (10) is also defined in $[0, t-1]$.

Example 8. Assume that

$$
\begin{aligned}
& \left(l_{1}, \eta_{1}\right)=\left(s_{3}, 0.4\right),\left(l_{2}, \eta_{2}\right)=\left(s_{2}, 0.2\right), \\
& \left(l_{3}, \eta_{3}\right)=\left(s_{1}, 0.1\right),\left(l_{4}, \eta_{4}\right)=\left(s_{5}, 0.2\right), \\
& \left(r_{1}, a_{1}\right)=\left(s_{1}, 0.1\right),\left(r_{2}, a_{2}\right)=\left(s_{1}, 0.3\right),
\end{aligned}
$$

$$
\begin{gathered}
\left(r_{3}, a_{3}\right)=\left(s_{1}, 0.002\right),\left(r_{4}, a_{4}\right)=\left(s_{1}, 0.03\right), \\
\left(c_{1}, b_{1}\right)=\left(s_{2}, 0.3\right),\left(c_{2}, b_{2}\right)=\left(s_{1}, 0.1\right) \\
\left(c_{3}, b_{3}\right)=\left(s_{1}, 0.2\right),\left(c_{4}, b_{4}\right)=\left(s_{1}, 0.3\right)
\end{gathered}
$$

then,

$$
\begin{gathered}
\left(r_{1}^{\prime}, a_{1}^{\prime}\right)=\left(s_{1}, 0.1\right)^{4\left(s_{2}, 0.3\right)}=\left(s_{2}, 0.4033\right), \\
\left(r_{2}^{\prime}, a_{2}^{\prime}\right)=\left(s_{1}, 0.3\right)^{4\left(s_{1}, 0.1\right)}=\left(s_{3}, 0.1721\right), \\
\left(r_{3}^{\prime}, a_{3}^{\prime}\right)=\left(s_{1}, 0.002\right)^{4\left(s_{1}, 0.2\right)}=\left(s_{1}, 0.0080\right)
\end{gathered}
$$

and

$$
\left(r_{4}^{\prime}, a_{4}^{\prime}\right)=\left(s_{1}, 0.03\right)^{4\left(s_{1}, 0.3\right)}=\left(s_{1}, 0.0157\right) .
$$

Therefore,

$$
\begin{gathered}
\left(r_{\sigma(1)}^{\prime}, a_{\sigma(1)}^{\prime}\right)=\left(s_{3}, 0.1721\right), \\
\left(r_{\sigma(2)}^{\prime}, a_{\sigma(2)}^{\prime}\right)=\left(s_{2}, 0.4033\right), \\
\left(r_{\sigma(3)}^{\prime}, a_{\sigma(3)}^{\prime}\right)=\left(s_{1}, 0.0157\right)
\end{gathered}
$$

and

$$
\left(r_{\sigma(4)}^{\prime}, a_{\sigma(4)}^{\prime}\right)=\left(s_{1}, 0.0080\right) .
$$

Thus,

$$
\begin{aligned}
& \text { ET-HLWG }{ }_{L, C}\left(\left(r_{1}, a_{1}\right),\left(r_{2}, a_{2}\right),\left(r_{3}, a_{3}\right),\left(r_{4}, a_{4}\right)\right) \\
& =\Delta\left(\prod_{j=1}^{4}\left(\Delta^{-1}\left(r_{\sigma(j)}^{\prime}, a_{\sigma(j)}^{\prime}\right)\right)^{\frac{\Delta^{-1}\left(l_{j}, \eta_{j}\right)}{\sum_{j=1}^{4} \Delta^{-1}\left(l_{j}, \eta_{j}\right)}}\right) \\
& =\Delta(1.6436)=\left(s_{2},-0.3564\right) .
\end{aligned}
$$

\section{MAGDM model and method with 2-tuple Linguistic assessments}

In the following, we apply the 2-tuple hybrid geometric aggregation operators to solve the MAGDM problems with 2-tuple linguistic assessments.

\subsection{MAGDM model description with 2-tuple linguistic assessments}

This subsection describes the MAGDM problem with 2tuple linguistic assessments.

Let $A=\left\{A_{1}, A_{2}, \cdots, A_{m}\right\}$ be a discrete set of $m$ possible alternatives and $F=\left\{a_{1}, a_{2}, \cdots, a_{n}\right\}$ be a finite set of $n$ attributes, where $A_{i}$ denotes the $i$ th alternative and $a_{j}$ denotes the $j$ th attribute. Let $D=\left\{D_{1}, D_{2}, \cdots, D_{t}\right\}$ be a finite set of $t$ experts, where $D_{k}$ denotes the $k$ th expert.

The expert $D_{k}$ provides his/her assessment information of an alternative $A_{i}$ on an attribute $a_{j}$ as a 2-tuple $r_{i j}^{k}=\left(s_{i j}^{k}, \alpha_{i j}^{k}\right)$ according to a predefined linguistic term set $S$, where $s_{i j}^{k} \in S$ and $\alpha_{i j}^{k} \in[-0.5,0.5)$ $(i=1,2, \cdots, m ; j=1,2, \cdots, n ; k=1,2, \cdots, t)$. Thus, the experts' assessment information can be represented by 
the 2-tuple linguistic decision matrixes $\boldsymbol{R}^{k}=\left(r_{i j}^{k}\right)_{m \times n}$ $(k=1,2, \cdots, t)$.

Suppose that the weight information of attributes and experts also can be represented by the 2-tuple linguistic information.

Let $\boldsymbol{W}=\left(\left(w_{1}, \theta_{1}\right),\left(w_{2}, \theta_{2}\right), \cdots,\left(w_{n}, \theta_{n}\right)\right)^{\mathrm{T}}$ be the 2-tuple linguistic weight vector of the attributes $a_{j}$ $(j=1,2, \cdots, n)$ and $\boldsymbol{C}=\left(\left(c_{1}, b_{1}\right),\left(c_{2}, b_{2}\right), \cdots,\left(c_{t}, b_{t}\right)\right)^{\mathrm{T}}$ be the 2-tuple linguistic weight vector of the experts $D_{k}$ $(k=1,2, \cdots, t)$, where $w_{j} \in S, c_{k} \in S, \theta_{j} \in[-0.5,0.5)$ and $b_{k} \in[-0.5,0.5) \quad(j=1,2, \cdots, n ; k=1,2, \cdots, t)$.

The problem concerned in this paper is how to rank alternatives or select the most desirable alternative(s) among the finite set $A$ based on the 2tuple linguistic assessment information given by the experts and the 2-tuple linguistic weight information of attributes and experts.

\subsection{The MAGDM method with 2-tuple Linguistic assessment Information}

In this subsection, we propose a new method based on the ET-WG and ET-HLWG operators to solve the MAGDM problems with 2-tuple linguistic assessments. The process and algorithm may be summarized as follows.

Step 1. Utilized the ET-WG operator to integrate the $i$ th line elements of the decision matrix $\boldsymbol{R}^{k}$, the individual overall preference value of the alternative $A_{i}$ given by the expert $D_{k}$ is derived as follows:

$$
\begin{aligned}
z_{i}^{k}=\left(s_{i}^{k}, \alpha_{i}^{k}\right) & =\mathrm{ET}^{-W G_{W}}\left(\left(s_{i 1}^{k}, \alpha_{i 1}^{k}\right),\left(s_{i 2}^{k}, \alpha_{i 2}^{k}\right), \cdots,\left(s_{i n}^{k}, \alpha_{i n}^{k}\right)\right) \\
& =\Delta\left(\prod_{j=1}^{n}\left(\Delta^{-1}\left(s_{i j}^{k}, \alpha_{i j}^{k}\right)\right)^{\frac{\Delta^{-1}\left(w_{j}, \theta_{j}\right)}{\sum_{j=1}^{n} \Delta^{-1}\left(w_{j}, \theta_{j}\right)}}\right),
\end{aligned}
$$

where $\boldsymbol{W}=\left(\left(w_{1}, \theta_{1}\right),\left(w_{2}, \theta_{2}\right), \cdots,\left(w_{n}, \theta_{n}\right)\right)^{\mathrm{T}}$ be the 2tuple linguistic weight vector of the attributes, $s_{i}^{k} \in S$ and $\alpha_{i}^{k} \in[-0.5,0.5)$.

Step 2. Used the ET-HLWG operator to integrate all the individual overall preference values $z_{i}^{k}=\left(s_{i}^{k}, \alpha_{i}^{k}\right) \quad(k=1,2, \cdots, t)$ of alternative $A_{i}$, the collective overall preference value of alternative $A_{i}$ is obtained as follows:

$$
\begin{aligned}
z_{i}=\left(s_{i}, \alpha_{i}\right) & =\text { ET-HLWG }{ }_{L, C}\left(\left(s_{i}^{1}, \alpha_{i}^{1}\right),\left(s_{i}^{2}, \alpha_{i}^{2}\right), \cdots,\left(s_{i}^{t}, \alpha_{i}^{t}\right)\right) \\
& =\Delta\left(\prod_{j=1}^{t}\left(\Delta^{-1}\left(s_{i}^{\prime \sigma(j)}, \alpha_{i}^{\prime \sigma(j)}\right)\right)^{\frac{\Delta^{-1}\left(l_{j}, \eta_{j}\right)}{\sum^{t} \Delta^{-1}\left(l_{j}, \eta_{j}\right)}}\right),
\end{aligned}
$$

where $\boldsymbol{L}=\left(\left(l_{1}, \eta_{1}\right),\left(l_{2}, \eta_{2}\right), \cdots,\left(l_{t}, \eta_{t}\right)\right)^{\mathrm{T}}$ is the linguistic weighted vector correlating with ET-HLWG, $\left(s_{i}^{\prime \sigma(j)}, \alpha_{i}^{\prime \sigma(j)}\right)$ is the $j$ th largest 2-tuple of 2-tuples $\left(s_{i}^{\prime k}, \alpha_{i}^{\prime k}\right)(k=1,2, \cdots, t)$ with $\left(s_{i}^{\prime k}, \alpha_{i}^{\prime k}\right)=\left(s_{i}^{k}, \alpha_{i}^{k}\right)^{t\left(c_{k}, b_{k}\right)}$, $\boldsymbol{C}=\left(\left(c_{1}, b_{1}\right),\left(c_{2}, b_{2}\right), \cdots,\left(c_{t}, b_{t}\right)\right)^{\mathrm{T}}$ is the 2-tuple linguistic weight vector of experts.

Step 3. Rank all the alternatives and select the best one(s) in accordance with $z_{i}=\left(s_{i}, \alpha_{i}\right)$ $(i=1,2, \cdots, m)$. If any alternative has the highest $z_{i}$ value, then it is the best alternative.

\section{A real application to evaluating university faculty for tenure and promotion}

In this subsection, a real case study of evaluating university faculty for tenure and promotion is examined to illustrate the proposed method in this paper.

Nanchang University of China intends to evaluate five faculties for tenure and promotion. The five faculty candidates (alternatives) are Information technology faculty $A_{1}$, Software faculty $A_{2}$, Humanities faculty $A_{3}$, Mathematics faculty $A_{4}$ and Chemistry faculty $A_{5}$, respectively. The university committee invites four experts $D_{k} \quad(k=1,2,3,4)$ from the other famous universities to evaluate these faculties. Since the expert $D_{3}$ has engaged in university evaluation for many years and accumulated rich experience, the university committee names the expert $D_{3}$ as the group leader which is responsible for the whole evaluating work.

Generally, many attributes should be used to evaluate these faculties. To improve the efficiency and rapidly make decision, three attributes are chosen by the four experts after preliminary screening. These attributes are teaching $a_{1}$, research $a_{2}$ and service $a_{3}$, respectively. These attributes are all qualitative attributes, it is reasonable for the experts to use linguistic variables or 2-tuples to represent the evaluation information of the faculties with respective to the attributes. Consequently, the five faculty candidates are to be evaluated using the 2-tuple linguistic information according to the linguistic term set:

$S=\left\{s_{0}=\right.$ extremely poor (bad); $s_{1}=$ very poor (bad); $s_{2}=$ poor (bad); $s_{3}=$ slightly poor (bad); $s_{4}=$ fair (important); $s_{5}=$ slightly good (important); $s_{6}=\operatorname{good}$ (important); $s_{7}=$ very good (important); $s_{8}=$ extremely good (important)\} 
by the four experts under these three attributes. The 2tuple linguistic decision matrixes provided by each expert are respectively as follows:

$$
\begin{aligned}
\boldsymbol{R}^{1} & =\left(\begin{array}{ccc}
\left(s_{0}, 0.4\right) & \left(s_{3}, 0.2\right) & \left(s_{8}, 0.1\right) \\
\left(s_{4}, 0.3\right) & \left(s_{1}, 0.4\right) & \left(s_{7},-0.2\right) \\
\left(s_{2}, 0.2\right) & \left(s_{4}, 0.3\right) & \left(s_{6}, 0.3\right) \\
\left(s_{1}, 0.3\right) & \left(s_{5},-0.4\right) & \left(s_{7}, 0.2\right) \\
\left(s_{7},-0.2\right) & \left(s_{8}, 0.1\right) & \left(s_{0}, 0.1\right)
\end{array}\right), \\
\boldsymbol{R}^{2} & =\left(\begin{array}{ccc}
\left(s_{2}, 0.1\right) & \left(s_{4}, 0.2\right) & \left(s_{6}, 0.1\right) \\
\left(s_{5},-0.3\right) & \left(s_{3}, 0.1\right) & \left(s_{6}, 0.2\right) \\
\left(s_{2}, 0.2\right) & \left(s_{7},-0.3\right) & \left(s_{6}, 0.3\right) \\
\left(s_{2}, 0.3\right) & \left(s_{1}, 0.4\right) & \left(s_{7}, 0.2\right) \\
\left(s_{6}, 0.2\right) & \left(s_{7},-0.1\right) & \left(s_{8}, 0.1\right)
\end{array}\right), \\
\boldsymbol{R}^{3} & =\left(\begin{array}{ccc}
\left(s_{4}, 0.3\right) & \left(s_{2}, 0.4\right) & \left(s_{7}, 0.3\right) \\
\left(s_{3}, 0.4\right) & \left(s_{2}, 0.1\right) & \left(s_{5},-0.2\right) \\
\left(s_{1}, 0.3\right) & \left(s_{4}, 0.3\right) & \left(s_{6}, 0.3\right) \\
\left(s_{5}, 0.1\right) & \left(s_{8},-0.3\right) & \left(s_{7}, 0.2\right) \\
\left(s_{7},-0.2\right) & \left(s_{7}, 0.4\right) & \left(s_{2}, 0.4\right)
\end{array}\right),
\end{aligned}
$$

and

$$
\boldsymbol{R}^{4}=\left(\begin{array}{ccc}
\left(s_{1}, 0.3\right) & \left(s_{0}, 0.4\right) & \left(s_{7}, 0.1\right) \\
\left(s_{3}, 0.3\right) & \left(s_{5}, 0.4\right) & \left(s_{8},-0.2\right) \\
\left(s_{1}, 0.2\right) & \left(s_{6}, 0.2\right) & \left(s_{8}, 0.3\right) \\
\left(s_{1}, 0.4\right) & \left(s_{5}, 0.3\right) & \left(s_{8},-0.2\right) \\
\left(s_{6}, 0.3\right) & \left(s_{3}, 0.1\right) & \left(s_{1}, 0.3\right)
\end{array}\right)
$$

With ever increasing complexity in real-life university evaluation management, it is very difficult to give precisely the linguistic assessment information on the expert weights and attribute weights according to the given linguistic term set in advance. For example, the experts think that the attribute $a_{3}$ is important and the weight may be $s_{6}$ but less than $s_{6}$, thus the weight of attribute $a_{3}$ can be represented using the linguistic 2tuple $\left(w_{3}, \theta_{3}\right)=\left(s_{6},-0.2\right)$. After the negotiation and investigation of the experts, they determine the 2-tuple linguistic weight vector $\boldsymbol{W}=\left(\left(w_{1}, \theta_{1}\right),\left(w_{2}, \theta_{2}\right),\left(w_{3}, \theta_{3}\right)\right)^{\mathrm{T}}$ of the attributes, where $\left(w_{1}, \theta_{1}\right)=\left(s_{8},-0.4\right)$, $\left(w_{2}, \theta_{2}\right)=\left(s_{1}, 0.3\right)$ and $\left(w_{3}, \theta_{3}\right)=\left(s_{6},-0.2\right)$.

As the stated earlier, the expert $D_{3}$, named as the group leader, has rich experience, knowledge and speciality in university evaluation. Obviously, his importance degree is extremely high and may be $s_{8}$ but less than $s_{8}$, therefore, the weight of expert $D_{3}$ can be represented using the linguistic 2-tuple $\left(c_{3}, \beta_{3}\right)=\left(s_{8},-0.1\right)$. Analogously, the 2-tuple linguistic weight vector $C=\left(\left(c_{1}, b_{1}\right),\left(c_{2}, b_{2}\right),\left(c_{3}, b_{3}\right),\left(c_{4}, b_{4}\right)\right)^{\mathrm{T}}$ of the experts can be obtained, where $\left(c_{1}, b_{1}\right)=\left(s_{5}, 0.1\right)$,

$$
\begin{aligned}
& \left(c_{2}, b_{2}\right)=\left(s_{1}, 0.2\right) \quad, \quad\left(c_{3}, b_{3}\right)=\left(s_{8},-0.1\right) \quad \text { and } \\
& \left(c_{4}, b_{4}\right)=\left(s_{3}, 0.4\right) .
\end{aligned}
$$

Next, we adopt the proposed method in this paper to solve this faculty evaluation problem.

Step 1. Combined the decision matrix $\boldsymbol{R}^{1}$ and $\boldsymbol{W}=\left(\left(w_{1}, \theta_{1}\right),\left(w_{2}, \theta_{2}\right),\left(w_{3}, \theta_{3}\right)\right)^{\mathrm{T}}$ with the ET-WG operator , the individual overall preference value of the faculty $A_{1}$ given by expert $D_{1}$ is generated as follows:

$$
\begin{aligned}
z_{1}^{1} & =\left(s_{1}^{1}, \alpha_{1}^{1}\right)=\mathrm{ET}^{-W_{W}}\left(\left(s_{11}^{1}, \alpha_{11}^{1}\right),\left(s_{12}^{1}, \alpha_{12}^{1}\right),\left(s_{13}^{1}, \alpha_{13}^{1}\right)\right) \\
& =\Delta\left(\prod_{j=1}^{3}\left(\Delta^{-1}\left(s_{1 j}^{1}, \alpha_{1 j}^{1}\right)\right)^{\frac{\Delta^{-1}\left(w_{j}, \theta_{j}\right)}{\sum_{j=1}^{3} \Delta^{-1}\left(w_{j}, \theta_{j}\right)}}\right)=\left(s_{2},-0.4245\right) .
\end{aligned}
$$

Similarly, we have

$$
\begin{gathered}
z_{2}^{1}=\left(s_{2}^{1}, \alpha_{2}^{1}\right)=\left(s_{5},-0.3446\right), \\
z_{3}^{1}=\left(s_{3}^{1}, \alpha_{3}^{1}\right)=\left(s_{4},-0.4646\right), \\
z_{4}^{1}=\left(s_{4}^{1}, \alpha_{4}^{1}\right)=\left(s_{3},-0.1438\right), \\
z_{5}^{1}=\left(s_{5}^{1}, \alpha_{5}^{1}\right)=\left(s_{1}, 0.3068\right) \\
z_{1}^{2}=\left(s_{1}^{2}, \alpha_{1}^{2}\right)=\left(s_{3}, 0.4007\right), \\
z_{2}^{2}=\left(s_{2}^{2}, \alpha_{2}^{2}\right)=\left(s_{5}, 0.5003\right), \\
z_{3}^{2}=\left(s_{3}^{2}, \alpha_{3}^{2}\right)=\left(s_{4},-0.3232\right), \\
z_{4}^{2}=\left(s_{4}^{2}, \alpha_{4}^{2}\right)=\left(s_{3}, 0.4531\right), \\
z_{5}^{2}=\left(s_{5}^{2}, \alpha_{5}^{2}\right)=\left(s_{7}, 0.0449\right) \\
z_{1}^{3}=\left(s_{1}^{3}, \alpha_{1}^{3}\right)=\left(s_{5}, 0.0323\right), \\
z_{2}^{3}=\left(s_{2}^{3}, \alpha_{2}^{3}\right)=\left(s_{1},-0.2670\right), \\
z_{3}^{3}=\left(s_{3}^{3}, \alpha_{3}^{3}\right)=\left(s_{3},-0.3065\right), \\
z_{4}^{3}=\left(s_{4}^{3}, \alpha_{4}^{3}\right)=\left(s_{6}, 0.0601\right), \\
z_{5}^{3}=\left(s_{5}^{3}, \alpha_{5}^{3}\right)=\left(s_{5}, 0.4575\right) \\
z_{1}^{4}=\left(s_{1}^{4}, \alpha_{1}^{4}\right)=\left(s_{2}, 0.2887\right), \\
z_{2}^{4}=\left(s_{2}^{4}, \alpha_{2}^{4}\right)=\left(s_{5},-0.1602\right), \\
z_{3}^{4}=\left(s_{3}^{4}, \alpha_{3}^{4}\right)=\left(s_{3},-0.0239\right), \\
z_{4}^{4}=\left(s_{4}^{4}, \alpha_{4}^{4}\right)=\left(s_{3}, 0.1016\right)
\end{gathered}
$$

and

$$
z_{5}^{4}=\left(s_{5}^{4}, \alpha_{5}^{4}\right)=\left(s_{3}, 0.1745\right) .
$$

Step 2. For the ET-HLWG operator, assume that the correlated 2-tuple weighted vector is $\boldsymbol{L}=\left(\left(l_{1}, \eta_{1}\right),\left(l_{2}, \eta_{2}\right),\left(l_{3}, \eta_{3}\right),\left(l_{4}, \eta_{4}\right)\right)^{\mathrm{T}}$, where $\left(l_{1}, \eta_{1}\right)=\left(s_{2}, 0.2\right)$, $\left(l_{2}, \eta_{2}\right)=\left(s_{5}, 0.1\right),\left(l_{3}, \eta_{3}\right)=\left(s_{7},-0.2\right)$ and $\left(l_{4}, \eta_{4}\right)=\left(s_{6}, 0.3\right)$. Then, used $\boldsymbol{C}=\left(\left(c_{1}, b_{1}\right),\left(c_{2}, b_{2}\right),\left(c_{3}, b_{3}\right),\left(c_{4}, b_{4}\right)\right)^{\mathrm{T}}$ and the ET-HLWG operator to integrate all the individual overall preference values $z_{1}^{k}=\left(s_{1}^{k}, \alpha_{1}^{k}\right) \quad(k=1,2,3,4)$ of faculty $A_{1}$, the collective overall preference value of faculty $A_{1}$ is thus derived as follows: 


$$
\begin{aligned}
z_{1} & =\mathrm{ET}-\mathrm{HLWG} \mathrm{G}_{L, C}\left(\left(s_{1}^{1}, \alpha_{1}^{1}\right),\left(s_{1}^{2}, \alpha_{1}^{2}\right),\left(s_{1}^{3}, \alpha_{1}^{3}\right),\left(s_{1}^{4}, \alpha_{1}^{4}\right)\right) \\
& =\Delta\left(\prod_{j=1}^{4}\left(\Delta^{-1}\left(s_{1}^{\prime \sigma(j)}, \alpha_{1}^{\prime \sigma(j)}\right)\right)^{\frac{\Delta_{j=1}^{-1}\left(l_{j}, \eta_{j}\right)}{4} \Delta^{-1}\left(l_{j}, \eta_{j}\right)}\right)=\left(s_{3}, 0.1561\right) .
\end{aligned}
$$

In the same way, we have

$$
z_{2}=\text { ET-HLWG }{ }_{L, C}\left(\left(s_{2}^{1}, \alpha_{2}^{1}\right),\left(s_{2}^{2}, \alpha_{2}^{2}\right),\left(s_{2}^{3}, \alpha_{2}^{3}\right),\left(s_{2}^{4}, \alpha_{2}^{4}\right)\right)
$$$$
=\Delta\left(\prod_{j=1}^{4}\left(\Delta^{-1}\left(s_{2}^{\sigma \sigma(j)}, \alpha_{2}^{\prime \sigma(j)}\right)\right)^{\frac{\Delta^{-1}\left(l_{j}, \eta_{j}\right)}{4} \sum^{4} \Delta^{-1}\left(l_{j}, \eta_{j}\right)}\right)=\left(s_{4}, 0.4690\right),
$$$$
z_{3}=\text { ET-HLWG }_{L, C}\left(\left(s_{3}^{1}, \alpha_{3}^{1}\right),\left(s_{3}^{2}, \alpha_{3}^{2}\right),\left(s_{3}^{3}, \alpha_{3}^{3}\right),\left(s_{3}^{4}, \alpha_{3}^{4}\right)\right)
$$$$
=\Delta\left(\prod_{j=1}^{4}\left(\Delta^{-1}\left(s_{3}^{\prime \sigma(j)}, \alpha_{3}^{\prime \sigma(j)}\right)\right)^{\frac{\Delta^{-1}\left(l_{j}, \eta_{j}\right)}{\sum_{j=1}^{4} \Delta^{-1}\left(l_{j}, \eta_{j}\right)}}\right)=\left(s_{3}, 0.0919\right),
$$$$
z_{4}=\mathrm{ET}-\mathrm{HLWG}_{L, C}\left(\left(s_{4}^{1}, \alpha_{4}^{1}\right),\left(s_{4}^{2}, \alpha_{4}^{2}\right),\left(s_{4}^{3}, \alpha_{4}^{3}\right),\left(s_{4}^{4}, \alpha_{4}^{4}\right)\right)
$$$$
=\Delta\left(\prod_{j=1}^{4}\left(\Delta^{-1}\left(s_{4}^{\prime \sigma(j)}, \alpha_{4}^{\prime \sigma(j)}\right)\right)^{\frac{\Delta^{-1}\left(l_{j}, \eta_{j}\right)}{\sum_{j=1}^{4} \Delta^{-1}\left(l_{j}, \eta_{j}\right)}}\right)=\left(s_{4},-0.0523\right)
$$

and

$$
\begin{aligned}
z_{5} & =\mathrm{ET}-\mathrm{HLWG} \mathrm{L}_{L, C}\left(\left(s_{5}^{1}, \alpha_{5}^{1}\right),\left(s_{5}^{2}, \alpha_{5}^{2}\right),\left(s_{5}^{3}, \alpha_{5}^{3}\right),\left(s_{5}^{4}, \alpha_{5}^{4}\right)\right) \\
& =\Delta\left(\prod_{j=1}^{4}\left(\Delta^{-1}\left(s_{5}^{\prime \sigma(j)}, \alpha_{5}^{\prime \sigma(j)}\right)\right)^{\frac{\Delta^{-1}\left(l_{j}, \eta_{j}\right)}{\sum_{j=1}^{4} \Delta^{-1}\left(l_{j}, \eta_{j}\right)}}\right)=\left(s_{4},-0.0451\right) .
\end{aligned}
$$

Step 3. Since $z_{2}>z_{5}>z_{4}>z_{1}>z_{3}$, the ranking order of the faculties is $A_{2} \succ A_{5} \succ A_{4} \succ A_{1} \succ A_{3}$, and therefore the best faculty is Software faculty $A_{2}$.

\section{Comparison analysis with the similar method}

To illustrate the superiority of the proposed method, we use the proposed method in this paper to solve the investment selection problem of $\mathrm{Wei}^{8}$, and then conduct a comparison analysis.

An investment company wants to invest a sum of money in the best option. There is a panel with five possible alternatives to invest the money: a car company $A_{1}$, a food company $A_{2}$, a computer company $A_{3}$, an arms company $A_{4}$ and a TV company $A_{5}$. The investment company must take a decision according to the four attributes: the risk analysis $a_{1}$, the growth analysis $a_{2}$, the social-political impact analysis $a_{3}$ and the environmental impact analysis $a_{4}$. The five possible alternatives $A_{i}(i=1,2,3,4,5)$ are to be evaluated using the linguistic term set $S=\left\{s_{0}=\right.$ extremely poor (EP); $s_{1}=$ very poor (VP); $s_{2}=$ poor (P); $s_{3}=$ medium (M);
$s_{4}=\operatorname{good}(\mathrm{G}) ; s_{5}=$ very good (VG); $s_{6}=$ extremely good (EG) $\}$ by three decision makers $D_{k}(k=1,2,3)$ under the above four attributes. They respectively construct the decision matrices $\boldsymbol{R}_{k}=\left(\tilde{r}_{i j}^{k}\right)_{5 \times 4}(k=1,2,3)$ as follows:

$$
\begin{aligned}
\boldsymbol{R}_{1} & =\left(\begin{array}{cccc}
M & G & P & P \\
P & V P & M & P \\
G & M & G & E P \\
V G & P & P & G \\
E G & E P & V P & M
\end{array}\right), \\
\boldsymbol{R}_{2} & =\left(\begin{array}{cccc}
P & M & V P & V P \\
V P & E P & G & G \\
M & G & P & E G \\
E G & V P & V P & M \\
P & V P & M & V P
\end{array}\right),
\end{aligned}
$$

and

$$
\boldsymbol{R}_{3}=\left(\begin{array}{cccc}
G & P & V P & V G \\
V P & G & P & G \\
V G & V P & G & P \\
G & V G & E G & V P \\
M & V P & M & G
\end{array}\right) .
$$

In $\mathrm{Wei}^{8}$, the linguistic weight vector of the attributes is $\boldsymbol{H}=\left(s_{2}^{\prime}, s_{0}^{\prime}, s_{1}^{\prime}, s_{3}^{\prime}\right)^{\mathrm{T}}$ using the linguistic term set $S^{\prime}=\left\{s_{0}^{\prime}=\right.$ extremely important; $s_{1}^{\prime}=$ very important; $s_{2}^{\prime}=$ important; $s_{3}^{\prime}=$ medium; $s_{4}^{\prime}=$ bad; $s_{5}^{\prime}=$ very bad; $s_{6}^{\prime}=$ extremely bad $\}$. For the ET-OWG operator of Wei ${ }^{8}$, the correlated linguistic weighted vector is taken as $\boldsymbol{V}=\left(s_{5}^{\prime}, s_{3}^{\prime}, s_{1}^{\prime}\right)^{\mathrm{T}}$. (Note that all the subscripts in the linguistic term sets $S$ and $S^{\prime}$ are minus 1 in order to be unified with Definition 1)

We suppose that the weight vector of decision makers is $\boldsymbol{\omega}=\left(s_{3}^{\prime}, s_{3}^{\prime}, s_{4}^{\prime}\right)^{\mathrm{T}}$ according to the linguistic term set $S^{\prime}$. In addition, for the ET-HLWG operator of this paper, we also take the correlated linguistic weighted vector as $\boldsymbol{V}=\left(s_{5}^{\prime}, s_{3}^{\prime}, s_{1}^{\prime}\right)^{\mathrm{T}}$.

Applying the proposed method in this paper, the above linguistic decision matrices, the linguistic weight vectors of the attributes and experts, and the correlated linguistic weighted vector should be firstly transformed into 2-tuple linguistic forms by using Eq. (3). Then, the collective overall preference values of alternatives can be obtained. Table 1 lists the collective overall preference values of alternatives obtained by the method $\mathrm{Wei}^{8}$ and method of this paper. 
Table 1 The collective overall preference values of alternatives obtained by both methods

\begin{tabular}{lllllll}
\hline Alternatives & \multicolumn{1}{c}{$A_{1}$} & \multicolumn{1}{c}{$A_{2}$} & $A_{3}$ & $A_{4}$ & $A_{5}$ & Ranking result \\
\hline Wei $^{8}$ & $\left(s_{3},-0.25\right)$ & $\left(s_{3}, 0.43\right)$ & $\left(s_{3}, 0.15\right)$ & $\left(s_{3}, 0.33\right)$ & $\left(s_{3},-0.32\right)$ & $A_{4} \succ A_{3} \succ A_{1} \succ A_{5} \succ A_{2}$ \\
This paper & $\left(s_{3}, 0.0040\right)$ & $\left(s_{3}, 0.4685\right)$ & $\left(s_{3}, 0.2450\right)$ & $\left(s_{3}, 0.2140\right)$ & $\left(s_{3},-0.1392\right)$ & $A_{3} \succ A_{4} \succ A_{1} \succ A_{5} \succ A_{2}$ \\
\hline
\end{tabular}

It is easily seen from Table 1 that the ranking results obtained by the method $\mathrm{Wei}^{8}$ and the method of this paper are slightly different. The difference is the ranking order of $A_{4}$ and $A_{3}$, i.e., $A_{4} \succ A_{3}$ by the former while $A_{3} \succ A_{4}$ by the latter. The worst alternative is $A_{2}$ by both methods, but the best alternative by the former is $A_{4}$, while the best alternative by the latter is $A_{3}$. Compared with the former, the main advantages of the latter mainly lie in the following:

(i) The latter sufficiently takes the importance degrees of different experts into consideration. Before utilizing the ET-HLWG operator, the individual overall preference values of alternatives should be firstly weighted by the expert weights and then the collective overall preference values of alternatives can be obtained. However, the former is based on the ET-WG and ETOWG operators, which doesn't consider the importance degrees of different experts at all.

In fact, different experts act as different roles in the decision process (such as the expert $D_{1}$ in Section 5). Some experts may assign unduly high or unduly low uncertain preference values to their preferred or repugnant objects. To relieve the influence of these unfair arguments on the decision results and reflect the importance degrees of all the experts, the latter first weights each individual overall preference value by using the corresponding expert weight, and then utilizes the ET-HLWG operator to aggregate all the individual weighted overall preference values of each alternative into the collective ones of alternatives. Therefore, the ET-HLWG or T-HLWG operator can make the decision results more reasonable through assigning low weights to those "false" or "biased" arguments. These advantages can not be reflected in the former.

(ii) The former is only suitable for the case where the weight information of attributes is in the form of the linguistic variables, whereas the latter can deal with the three cases: the linguistic variables, the 2-tuples and numerical values for the weight information of attributes and experts.

If the weight information of experts is given by linguistic variables or 2-tuples, the ET-HLWG operator can be used to integrate the individual overall preference values of alternatives into the collective ones; If the weight information of experts is given by the numerical values, we can use the T-HLWG operator to replace the ET-HLWG operator to derive the collective overall preference values of alternatives, which demonstrates that the latter is of universality and flexibility.

\section{Conclusions}

The traditional aggregation operators are generally suitable for aggregating the information taking the form of numerical values, and yet they will fail in dealing with linguistic information. A new decision method is proposed for the MAGDM problem with 2-tuple linguistic assessments. Firstly, the operation laws for 2tuple linguistic information are defined. After reviewing the existing 2-tuple linguistic geometric aggregation operators, some new hybrid geometric aggregation operators with 2-tuple linguistic information are developed including THWG, T-HLWG and ET-HLWG operators. The THWG operator generalizes both the TWG and TOWG operators. The ET-OWG operator is a special case of the T-HLWG operator.

The decision method proposed in this paper is based on hybrid geometric aggregation operators which can sufficiently consider the importance degrees of different experts and thus relieve the influence of those unfair arguments on the decision results. The proposed hybrid geometric aggregation operators with 2-tuple linguistic information enlarge the research content on 2tuple linguistic information and enrich the ideas for solving the MAGDM problems with linguistic information.

However, how to reasonably determine the linguistic (or 2-tuple linguistic) weighted vector correlating with these hybrid geometric aggregation operators is a critical problem, which will be investigated in the near future.

\section{Acknowledgements}

The author would like to thank Editors-in-chief Dr. L. Martínez Lopez and anonymous reviewers for their insightful and constructive comments. This work was partially supported by the National Natural Science Foundation of China (Nos. 71061006, 61263018), the Humanities Social Science Programming Project of Ministry of Education of China (No. 09YGC630107), the Natural Science Foundation of Jiangxi Province of China (No. 20114BAB201012) and the Science and Technology Project of Jiangxi province educational department of China (Nos. GJJ12265 and GJJ12740) 
and the Excellent Young Academic Talent Support Program of Jiangxi University of Finance and Economics.

\section{References}

1. Jiang, Y. P., Fan, Z. P., Ma, J. A method for group decision-making with multi-granularity linguistic assessment information. Information Sciences, 178(4) (2008) 1098-1109.

2. Herrera, F., Herrera-Viedma, E. Linguistic decision analysis: Steps for solving decision problems under linguistic information. Fuzzy Sets and Systems, 115(2000) 67-82.

3. Parreiras, R. O., Ekel, P. Ya., Martini, J. S. C., Palhares, R. M. A flexible consensus scheme for multicriteria group decision making under linguistic assessments. Information Sciences, 180(7) (2010) 1075-1089.

4. Herrera, F., Martínez, L., Sánchez, P. J. Managing non-homogeneous information in group decisionmaking. European Journal of Operational Research, 166(1) (2005) 115-132.

5. Xu, Z. S. A method based on linguistic aggregation operators for group decision making with linguistic preference relations. Information Sciences, 166 (2004) 19-30.

6. Xu, Z. S. Uncertain linguistic aggregation operators based approach to multiple attribute group decision making under uncertain linguistic environment. Information Sciences, 168 (2004) 171-184.

7. Wei, G. W. Uncertain linguistic hybrid geometric mean operator and its application to group decision making under uncertain linguistic environment. International Journal of Uncertainty, Fuzziness and Knowledge-Based Systems, 17(2) (2009) 251-267

8. Wei, G. W. A method for multiple attribute group decision making based on the ET-WG and ET-OWG operators with 2-tuple linguistic information. Expert Systems with Application, 37(12) (2010) 7895-7900.

9. Merigo, J. M., Casanovas, M., Martínez, L. Linguistic aggregation operator for linguistic decision making based no the Dempster-Shafer theory of evidence. International Journal of Uncertainty, Fuzziness and Knowledge-Based Systems, 18(3) (2010) 287-304.

10. Herrera, F., Martínez, L. A 2-tuple fuzzy linguistic representation model for computing with words. IEEE Transactions on Fuzzy Systems, 8 (2000) 746752.

11. Herrera, F., Martínez, L. An approach for combining linguistic and numerical information based on 2-tuple fuzzy linguistic representation model in decisionmaking. International Journal of Uncertainty,
Fuzziness, Knowledge-Based Systems, 8 (2000) 539562.

12. Herrera, F., Martínez, L. A model based on linguistic 2-tuple for dealing with multi-granular hierarchical linguistic contexts in multi-expert decision making. IEEE Transactions on Systems, Man, and Cybernetics, 31 (2001) 227-234.

13. Herrera-Viedma, E., Martinez, L., Mata, F., Chiclana, F. A consensus support system model for group decision-making problems with multi-granular linguistic preference relations. IEEE Transactions on Fuzzy Systems, 13 (2005) 644-658.

14. Liu, P., Jin, F., Methods for aggregating intuitionistic uncertain linguistic variables and their application to group decision making, Information Sciences (2012), doi: 10.1016/j.ins.2012.04.014.

15. Jiang, Y. P., Fan, Z. P. Property analysis of the aggregation operators for 2-tuple linguistic information. Control and Decision, 18(6) (2003) 754757

16. Yang, W., Chen, Z. P. New aggregation operators based on the Choquet integral and 2-tuple linguistic information. Expert Systems with Applications, 39 (2012) 2662-2668.

17. García, J. M. Tapia, Moral, M. J. del, Martínez M. A., Herrera-Viedma E. A consensus model for group decision making problems with linguistic interval fuzzy preference relations. Expert Systems with Applications, 39 (2012) 10022-10030.

18. Wei, G. W., Zhao, X. F. Some dependent aggregation operators with 2-tuple linguistic information and their application to multiple attribute group decision making. Expert Systems with Applications, 39 (2012) 5881-5886.

19. Wei, G. W. 2-tuple linguistic multiple attribute group decision-making with incomplete attribute weight information. Systems Engineering and Electronics, 30(2) (2008) 273-277.

20. Wei, G. W., Lin, R. Method of grey relational analysis for multiple attribute group decision-making based on 2-tuple linguistic information. Systems Engineering and Electronics, 30(9) (2008) 16861689

21. Xu, Y. J., Merigó, José M., Wang, H. M. Linguistic power aggregation operators and their application to multiple attribute group decision making. Applied Mathematical Modelling, 36(11) (2012) 5427-5444.

22. Wei, G. W. Grey relational analysis method for 2tuple linguistic multiple attribute group decision making with incomplete weight information. Expert Systems with Application, 38(5) (2011) 7895-7900.

23. Wei, G. W. Some generalized aggregating operators with linguistic information and their application to 


\section{S. P. Wan}

multiple attribute group decision making. Computers \& Industrial Engineering, 61(1) (2011) 32-38.

24. Chang, K. H., Wen, T. C. A novel efficient approach for DFMEA combining 2-tuple and the OWA operator. Expert Systems with Applications, 37(3) (2010) 2362-2370.

25. Zhang, Y., Fan, Z. P. An approach to linguistic multiple attribute decision making with linguistic information based on ELOWA operator. Systems Engineer, 24(12) (2006) 98-101.

26. Wang, X. R., Fan, Z. P. Method for group decisionmaking based on 2-tuple linguistic information processing. Journal of Management Science in China, 6(5) (2003) 1-5.

27. Wang, W. P. Evaluating new product development performance by fuzzy linguistic computing. Expert Systems with Applications, 36(6) (2009) 9759-9766.

28. Herrera, F., Herrera-Viedma, E., Martínez, L. A fuzzy linguistic methodology to deal with unbalanced linguistic term sets. IEEE Transactions on Fuzzy Systems, 16(2) (2008) 354-370.
29. Espinilla, M., Liu, J., Martínez, L. An extended hierarchical linguistic model for decision-making problems. Computational Intelligence, 27 (3) (2011) 489-512.

30. Martínez, L., Herrera, F. An overview on the 2-tuple linguistic model for computing with words in decision making: extensions, applications and challenges. Information Sciences, 207(1) (2012) 1-18.

31. Rodríguez, R. M., Martínez, L. An analysis of symbolic linguistic computing models in decision making. International Journal of General Systems, 42(1) (2013) 121-136.

32. Herrera, F., Herrera-Viedma, E., Martínez, L. A fusion approach for managing multi-granularity linguistic term sets in decision-making. Fuzzy Sets and Systems, 114 (2000) 43-58.

33. Torra V., Narukawa, Y. Modeling Decisions: Information Fusion and Aggregation Operators. (Springer-Verlag, Berlin, Germany, 2007). 